as decided as it was when the cloth, very perfectly wet, had Once more, putting the cloth end under water, holding the tube uearly horizontal, and blowing by the mouth ap plied to the other end, the water which had risen in to the that no air escaped until the air-pressure within exceeded pe the water pressure on the outside of the cloth by the equiva-
lent of a little more than nine inches of water; and when blown with a pressure just a very little more than that which sufficed to produce a bubble from any part of the cloth, bubbles es

area of the cloth.
The accompanying sketch represents the application to the navigational depth gauge. The wider of the two communicating tubes, shown uppermost in the sketch, has
its open mouth guarded by very fine cotton cloth tied across it. The tube shown lower in the diagram is closed for the tity of water (whicl had been forced into it during the descent of the gauge to the bottom of the sea) is retained in it while the gauge is heing towed up to the surface in some
such oblique position as that shown in the sketch. While this is being done the water in the wide tube is expelled by the expanding air. The object of the cloth guard is to secure that this water is expereard, the last a rop before any
air escapes; and that afterward, whe the bauge is being
towed wildly along the surface from wave to wave by a steamer running at fourteen or sixt

she instrument. A NEW PROCESS FOR THE METALLURGIC By Edward A. Parneli, F.C.S.

THE subject to which I have the gratification of inviting your' attention, namely, the effective and remunerative treatimportant problem in metalluroy. It is well known that the presence of zinc in onliserable quantity in ores con-
taining other metals has a very injurious influence in the ordinary smelting processes for the ext raction of the latter. much zinc necessitates additional operations in order to obtain copper of gool quality; and all the zinc originally prespresence of much zinc in lead ores, when the ordinary smelting processes are pursued; not only are the operations lead. Hence it follows that copper ores containing much taining much zinc are rejected by the lead smelter.

Further, ores of this complex character are not adapted to the use of the zinc or spelter manufacturer. From the cost of earthen retortsforms a considerable item in his working charges, it is essential that his raw material contain a
considerable proportion of zinc: less than 25 per cent. considerable proportion of zinc: less than 25 per cent.
would be rearded as unsuitable. Not only so, but the presence of certain other metals, especially lead, is highly objectionahle to the spelter make from their injurious ac-
tion on the earthen retorts. Zinc ore containing 8 per cent. of lead would be discarded.

Hence the necessity of resorting to some means of separation before having recourse to the ordinary smelting proalways adopted wherever it is practicable. In ordinary mixed ores containing galena and blende, this is easily ac-
complished by the great difference between the specific gravities of these two minerals; but in many cases separa-
tion by dressing is impracticable. Thus blende and copper py rites resemble each other in density too closely to allow py rites resember ench dressing. Again, blende and galena are
of separation by dound so intimately mixed or combined (forming apparently a homogeneous mineral) that their separation by dressing is too difficult to be practiced on the large scale
in fact, this is in some cases quite impossible. The plumbiin fact, this is in some cases quite impossible. The plumbi
ferous blende found in Anglesea, commonly known as ferous blende found in Anglesea, commonly known a cripets ores also exist, the raising of which would be very
protitale were it not for the contaminating influence of 20 per cent. and upwards of zinc; but hitherto the highest
prices paid for such by the smelter have been unremunera-
tive to the miner. The cupriferous blende found in great quantities at Ain Barbar, in Algeria, is of this kind. The extraction of zinc from such orcs in a useful form has
often been attempted by means of hydrochloric acid, after often been attempted by means of hydrochloric acid, after
calcination of the ore, with the view of decomposing the
chloride of zinc by lime. Serious impediments, however, chloride of zinc by lime. Serious impediments, however,
to this method have prevented it from being adopted, to this method have prevented it riam the difficulty of washing the oxide of zinc from the chloride of calcium and obtaining it in a dense form,
suitable for the spelter manufacturer; also, the injurious in fluence of the presence of chlorine in any form in the sub-
sequent smelting of the residue containing lead and silver. of course be easily effected by sulphuric acid, but the great objection to this method has been the difficulty (hitherto taining oxide of zinc from the sulphate, in a form suitable for the spelter manufacturer. In the process to which I
would now invite your attention this difficulty is completely

When heated alone, sulphate of zinc requires a very high temperature to effect its decomposition. Such a method is impracticable on the large scale; but when mixed with a
small proportion of a deoxidizing agent, sufficient to take one equivalent of oxygen from the sulphate, it is easily de-
composed with the production of oxide of zinc and sulphurous acid. A mixture of 2 equivs. of zinc sulphate with 1 equiv. of carbon, heated to dull redness, affords oxide of
zinc. With a larger proportion of carbon, sulphide of zinc is produced. Sulphide of zinc, whether artificial or native,

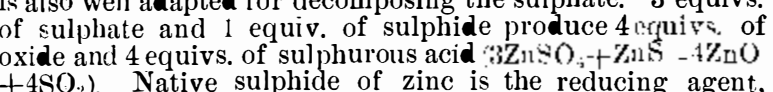
$+4 \mathrm{SO},)_{2}$. Native sulphide of zinc is the reducing agent,
which i prefer on the large scale for making oxide of zinc
suitable for the zinc manufacturer.

I will now briefly describe the routine of operations at pany, which have been erected for carrying out the process The principit ores operated on are the following, neither of which is "dressable."
1. Complex ore from Cavalo (Algeria), containing, as sul-
phides-Zinc, 17 per cent.; lead, 16 per cent.; silver, 20

2. Cupriferous blende from Ain Barbar (Algeria), contain-

3. Complex ore from Italy, containing-Zinc, 20 per cent ad. 12 per cent.; copper, 5 per cent.; also silver.

4. "Bluestone" from Anglesea, containing-Zinc, 28 per
nt.; lead, 12 per cent.; silver, 12 ounces per ton; also gold and copper.

5. Ore from Constantine (Algeria) containing-Zinc, 12 per ton; also gold.
unces per to

After having been ground sufficiently to pass through a ined with exposure to air, at a moderate heat. This calcination is effected in large muffle furnaces, the gas from
which, when containing a sufficient proportion of sulphurwhich, when containing a sufficient proportion of sulphur-
ous acid for making sulphuric acid, is conveyed to leaden metals are thus converted into oxides and sulphates. A dull red heat is found by experience most favorable to the the decomposition of ferrous and ferric sulphates. Th volving pan lined with lead (invented by Mr. J. W. Chenall)
ncutral licuors are first run off; afterwards excess of acid i neutral liquor's are first run off; afterwards excess of acid is
introduced, and the acid liquors thus obtained, together with subsequent washings by water, are used for pro
neutral liquors from a fresh charge of calcined ore

The solution of sulphate of zinc thus obtained of course contains copper when that metal was present in the ore. Of iron it contains very little, provided the ore had been prophuric acid combining by perference with oxide of zinc. I mention, in passing, that a solution of ferric sulphate
in dacomposed when warmed with oxide of zinc, with pre-
cipitation of ferric oxide and production of sulphate of From the clear neutral liquor copper is next precipitated the usual way, either as metallic copper by means of iron or zinc, or as sulphide. The solution of sulphate of zinc is then concentrated by evaporation, and mixed when it be-
gins to thicken with finely ground blende, in the proportion of one equivalent to three equivalents of zinc sulphate. This
mixture, after being further dried, is lastly heated to red. mixture, after being further dried, is lastly heated to red
ness in a muffle furnace. The mutual reaction which I have already described takes place with production of oxide of
zinc and sulphurous acid. The latter, having no admix ture of gases derived from the fire, is conveyed to leaden
chambers for the reproduction of sulphuric acid. The oxide of zinc thus obtained is in a condition well sited for the manufacture of metallic zinc in the ordinary way. Its strength and purity of course depend to some ex-
tent on that of the blende used as the reducing agent. When the latter contains about 45 per cent. of zinc, the oxide as
withdrawn from the furnaces contains about 62 per cent. of withdrawn from the furnaces contains about 62 per cent. of
zinc. It contains no impurity which is of any inconvenicipal impurty is oxide of iron, derived partly from the cipal impurity is oxide of iron, aderived partly from the
as a precipitant for the copper. The impurity which the zine manufacturer regards as most deleterious-namely, lead--is reduced to a minimum, being only the small pro-
portion contained in the added blende. The same may be
said respecting calcium. Occasionally the oxide of zinc contains a little magnesium,
cold owing to the presence of magnesian minerals in the raw ore But tlip metal is not present in the oxide in the objectionIt may be interesting for me to remark here that sulphate of
magnesia is easily decomposed by blende and other reduc ing agents in a manner corresponding to sulphate of zinc. nesia and carbon is moderately heated, magnesia is obtained
mixed with very little undecomposed sulphåte. Magnesia "lensy prepared corresponds in density to what is known a method of preparing that article will be found far more
ready and economical than the common method of precipitation as carbonate and calcination.
I have now to revert to the portion of the ore left undis I have now to revert to the portion of the ore left undisolved after treatment with dilute sulphuric acid. This of
ourse, contains all the lead originally present in the ore. The same may be said of the gold and silver. It might be rendered soluble during the calcination of the ore. This is
doubtless the case to a small extent, but I have always found tbat the minute quantity of silver thus rendered solule is less than corresponds to the trace of chlorine present soluble in solution of sulphate of zinc.

For the further treatment of this residue the ordinary
well-known smelting processes are resorted to, the products being argentiferous and a uriftrous lead, and also copper regulus, which generally contains both gold and silver. At
the works of the Swansea Zinc Ore Company, the smelting of the residue is effected in cupolas; an important appen Messrs. Wilson and French, of Sheffield (brought before the notice of the British Association last year), in which the
gases from the furnace are forced under water and allowed gases from the furnace are forced under water and allowed ery satisfactorily.

In conclusion I would remark, as will doubtless have is capable of other applications besides the conplex ores I have referred to. Such, for example, as the residue of blende
after the richer portion has been separated. Immense quantities of such residue exist containing 22 per cent. of zinc, the further dressing of which is not profitable. This
is of no value in its present condition, but capable or profitable application by the process I have described. It may also be applied to lead fume containing zinc, and to the crude
sulphide of zinc derived from burnt iron pyrites containing
blende, of which a litreg quantity is used in Germany for
making sulphuric scitit.

In repiy to inquiries respecting the density of the oxide of zinc thus prepared (a matter of great importance to the
spelter manufacturer), Mr. Parnell stated that it is rather
greater than that of ordinary calcined calamine. The oxide is in every respect admirably suited to the mannfacture of
ELECTRO-CHEMICAL ANALYSIS OF METALS. THE convenience of the port of Swansea, Wales, together with the extensive anthracite mines in the neighborhood,
has made the town the principal seat of the copper trade of has made the town the principal seat of the copper trade of
Great Britain; in fact, it has been estimated that nine-tenths of the copper used in England is from Swansea and its en-
virons. Enormous qnantities of copper ore are brought hither for smelting from Cuba, North and South America, Australia, Spain, Algeria, etc. With the manufacture of coptralia is also associated that of other metals, precious or
rare, such as tin, silver, nickel, and cobalt. The ores as they arrive are placed in piles under sheds on the wharves,
and, before being sold, are analyzed on the spot by the con signees. In analyzing the ores, some of the larger houses
have adopted an electro-chemical process which is remarkable for its power, rapidity, and simplicity. It has been in
use for about a year, and bids fair to entirely replace the old use for about a year, and bids fair to entirely replace the old
processes by dry way. The copper ore is dissolved in nitric processes by dry way. The copper ore is dissolved in nitric
acid, and the solution, properly neutralized. is submitted to
the action of a thermo electric pile, heated by a gas flame The constancy of this pile is tested by means of a volta meter, which, ir construction, is something like that of $\mathbf{M r}$.
Warren de la Rue, and in wlich is decomposed a definite Warren de la Rue, and in wl,ich is decomposed a definite
number of cuhic centimeters of gas per minute. When the number of cuhic centimeters of gas per minute. When the
electro-chemical decomposition floes not give the requisite is formed of two alloys of bismuth the proportions used

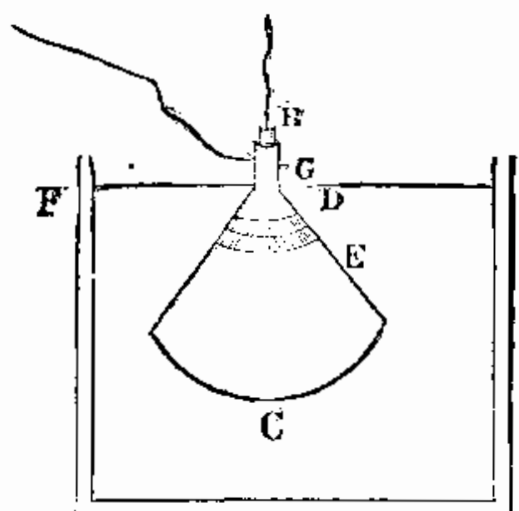

ELECTRO-CHEMICAL ANALYSIS OF METALS.

being unknown, since the alloys are manufactured in Ger might, however, it should be understood, be replaced by any
pile which is sufficiently constant. The essential part of the process, outside of the art of making the solutions, lies in
the form given to the poles and in the manner of using the form given to the poles and in the manner of using
lhem: The negative pole, $C$ (see cut), in which the copper interior passes a platinum wire inclosed in a glass tube, B, designed to prevent contact. The deposit of copper takes place on the internal as well as the external surface of the
funnel. When the pile is sufficiently weak and constant the deposit formed is very adherent and possesses a magnificent ort of difficulty. The optration usually takes from six to even hours, and, when tirished, there is nothing to do but weigh the platinum cone carefully, and thus determine the
weight of the copper deposited. To ascertain whether any copper still remains in the liquid, the funnel is again ima thin film at the upper part of the cone. If no deposit forms, it is a sure proof that no copper remains, and the
operation is, therefore, practically finished. This same pro ess may serve for the analysis of any metal whatever, proided the other metals present be precipitated, and that no would form a certain amount of platinum chloride, which would injure the pole and vitiate preceding determinations.

LEAD-HOW TO COAT ARTICLES THEREWITHTHE GALENIZING PROCESS.

Professor Emerson Reynolds thus describes one of the best methods of applying his new process of galenizing, or olid sodic hydrate $(\mathrm{NaOH})$ or an equivalent of other suitable hydrate, dissolve it in 1.75 liters of water, and add to the
liquid 17 grammes of lead nitrate $\left(\mathrm{Pb}_{2} \mathrm{NO}_{3}\right)$, or an equivaliquid 17 grammes of lead nitrate $\left(\mathrm{Pb} 2 \mathrm{NO}_{3}\right)$, or an equiva

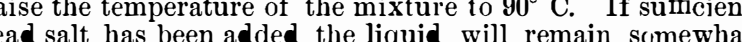
turbid after heating, and must then be rapidly strained or filtered through asbestos, glass-wool, or other suitable mawell mixed with 100 cubic centimeters of hot water con taining in solution 4 grammes of sulpho-urea or thio-car-
bamide. If the temperature of the mixture be maintained bamide. If the temperature of the mixture be maintained adherent film or layer nuickly takes place on any object be in a perfectly clean condition and suitable for the purpose. When the operation is properly conducted a lay er of be easily polished by means of the usual leather polisher. It is not necessary to deposit the galena from hot liquids,
but the deposition is more rapid than from cold solutions. The most convenient solution for deposition on brass is thus prepared: Take a goluntity of soda lye containing $1 \frac{1}{2}$
ounces of real soda $(\mathrm{NaOH})$ : dissolve in this, with the aid of heat, 3 ounces of tartate of lead, and just before diluting of heat, 3 ounces of tartate of lead, and just before diluting
the solution to one gallon of cold water, add 5 drachms of sulpho-urea previously dissolved in a small quantity of hot water. The articles are to be immediately immersed in this
bath, and the temperature raised to boiling. When the desired tint is obtained the articles are to be removed, washed,
and polished. The above solution can be used for glass or and polished. The above solution can be used for glass or
porcelain, hot or cold if the proportion of alkali be reduced ne-third or thereabouts.

\section{SOAP IN POMADES.}

This is a decided improvement. Before the perfume an ounce of solp, dissolved with $21 / 2$ grains of borax in bot
water, shoult be added to $3 \mathrm{lb}$. of the pomade. This makes the pomade snow white and very unctuous. Another ad
vantage is that a third of its weight of water can be incor vantage is that a third of its weight of wat.
porated with it.-Zeitssihr. $d$. osterr. $A$. $V$. 